\title{
Collagenous Gastritis
}

National Cancer Institute

\section{Source}

National Cancer Institute. Collagenous Gastritis. NCI Thesaurus. Code C122082.

A rare type of gastritis characterized by gastric subepithelial collagen deposition and inflammatory infiltrates in the lamina propria. The pathogenesis of this disorder is unclear although an association with autoimmune disorders has been reported. It affects both children and adults. Children present with iron deficiency anemia and have a nodular stomach on gastroscopy. Adults present with chronic watery diarrhea and may have an associated collagenous colitis. 